\title{
\#WhyWeDoResearch: Raising research awareness and opportunities for patients, public and staff through Twitter
}

\author{
Emma Yhnell - Cardiff University, UK \\ Hazel A. Smith - Irish Research Nurses Network, Ireland \\ Kay Walker - \#WhyWeDoResearch patient ambassador, UK \\ Claire L. Whitehouse* - \#WhyWeDoResearch originator, James Paget University \\ Hospitals NHS Foundation Trust, UK
}

\begin{abstract}
The \#Why WoDoResearch campaign was set up in 2014 and was originally planned to run locally, in Norfolk, at the James Paget University Hospitals NHS Foundation Trust (JPUH) for 12 days in December. Within four days, the campaign was being utilized nationally by other trusts and charities. By the New Year of 2015 it became international and had reached Australia and Canada. The intended audience for the campaign is broad and includes: patients, the general public, all staff working in health care and/or research including (but not limited to) National Health Service (NHS), commercial companies, charities and schools. The campaign has become a community where patients, staff and public alike can share their voices about health research on an equal playing field. Each year, to coincide with International Clinical Trials Day (ICTD) on 20 May, a \#WhyWeDoResearch 'Tweetfest' is hosted. This includes a number of 'tweetchats' at set times throughout the Tweetfest. Tweetchats are hosted by experts in particular diseases or other areas. Patients and patient groups are included in this group of experts. This article uses the \#WhyWeDoResearch campaign annual Tweetfest to demonstrate how social media can be utilized to raise awareness of health research around the world.
\end{abstract}

Keywords: Twitter; public; patients; health care; social media

\section{Key messages}

- The \#Why WeDoResearch campaign has become a community to raise research awareness, to share knowledge and experiences, and to connect researchers, patients and the public around the world.

- \#WhyWeDoResearch provides a level platform for patients, public and staff to discuss research issues, share a voice and be heard.

- \#WhyWeDoResearch has over 400 million impressions, is used by over 45,000 Twitter accounts and has a reach of 23 countries. 


\section{Background}

The \#WhyWeDoResearch (http://whywedoresearch.weebly.com) campaign was set up as a way of introducing the James Paget University Hospitals NHS Foundation Trust (JPUH) (@JPUHResearch) research team to the local population through the Twitter social media platform in December 2014. It was a Christmas campaign that utilized Twitter to share photographs of staff members and others holding a placard describing why they were involved in research (see Figure 1). Within four days, the social media hashtag was being used nationally by trusts and charities. Within three weeks, it had reached an international audience, with researchers from Australia, Spain and Canada tweeting their own \#WhyWeDoResearch quotations and photographs.

Figure 1: Representative images from the \#WhyWeDoResearch campaign

A. An expectant mother stating that she takes part in research to keep mothers and babies safe

B. A baby with a placard important to her mother
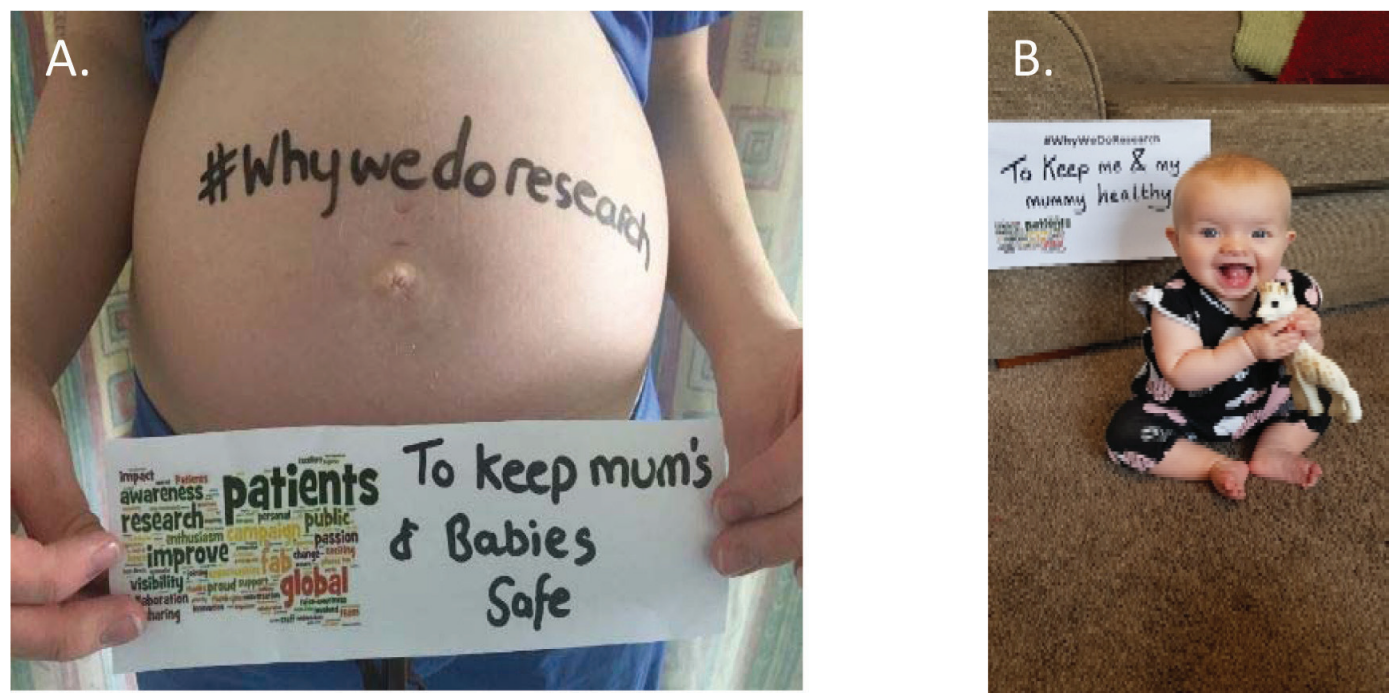

Credit: 1A @JamesPagetNHS

Credit: 1B @ClaireW_UK

The \#Why WeDoResearch campaign has since become the most utilized Twitter research community globally, providing an open and equal playing field for staff, patients and the public to discuss, share and learn about research.

\section{Background to social media, and patient and staff involvement}

Social media brings a new dimension to health-care research as it offers a level platform for discussion among patients, the public and health-care professionals (Gibbs et al., 2015). Recent years have seen increasing interest in calls for health-care professionals to focus on improving the patient experience and the engagement of patients in their own care (Chauhan et al., 2012; Househ, 2013; Smailhodzic et al., 2016), although little attention has been paid to understanding the impact and opportunities of social media. At the same time, patients themselves are utilizing social media as a tool to share experiences, often through blogs and other formats (Greaves et al., 2013). Any direct benefits for patients who use social media are (as yet) little explored, but a small 
number of studies have found that patient voices can be stronger and more clearly heard when they engage with (and lead on) social media activities (Househ et al., 2014; Antheunis et al., 2013). Koumpouros et al. (2015) explored the importance of patient engagement and analysed patients' use of social media. They concluded that healthcare organizations and individuals should adopt social media marketing in their daily practice in order to meet the demands and needs of patients and match their growing technological savvy, a notion echoed by Moorhead et al. (2013) and Ventola (2014).

While there is growing evidence about the impact, benefits and limitations of social media use for patients in health care (De Martino et al., 2017; Cordos et al., 2017), there remains a paucity of literature focusing on patient leadership in the same arena, and the impact this has on patients' experiences, learning and outcomes. Quantitative statistics were obtained through @WeGizmos to evaluate Tweetfest - an event held each year on 20 May to coincide with International Clinical Trials Day (ICTD). To assist the robustness of feedback reviews, qualitative responses were analysed using thematic analyses.

This article describes how patients and the public are engaged, involved and supported in leading tweetchats throughout \#Why WeDoResearch Tweetfests. We also sought to analyse the unique experience of patients and staff leading on tweetchats, and the subsequent impacts that being part of a global health-care research campaign had on their learning and understanding.

\section{Tweetchats and Tweetfest}

\#WhyWeDoResearch tweetchats are held approximately monthly, with a specific Tweetfest covering International Clinical Trials Day annually (schedules for the 2016, 2017 and 2018 Tweetfests are shown in Figures 2, 3 and 4). A tweetchat is an hour-long live discussion, which anyone can join at a predetermined time and date using the hashtag \#WhyWeDoResearch. Tweetchats are designed to engage the audience and Twitter followers about specific research topics, to share learning and experiences, and to raise awareness of research opportunities about a particular topic. Tweetchats are hosted by \#WhyWeDoResearch originator @ClaireW_UK, @smithhazelann and/or guest hosts who are either working in a research area or are a patient with a particular research interest in a disease or process.

Tweetchat hosts are provided with a toolkit of materials that allows them to develop a title and set questions to be launched via Twitter every ten to fifteen minutes within the hour. Tweetchats have two or more hosts to manage the scale of participation, and to support those hosting for the first time.

In 2016, \#WhyWeDoResearch ran the world's first research Tweetfest, which included 19 tweetchats over one week. In 2017, this increased to 29 tweetchats over two weeks with 51 hosts. For the two-week Tweetfest, the times, dates, titles and presenters of the chats were all included in the schedule, as well as on the website, and this was advertised prior to the event (see Figure 3). Tweetchats included a range of topics and were hosted over lunchtimes, evenings and weekends to maximize participation. The Tweetfest for 2018 was reduced to 14 tweetchats. Titles were voted for by the \#WhyWeDoResearch community in the months preceding International Clinical Trials Day in May (see Figure 4). Tweetchats were hosted by patients and/or patient groups, and support was provided by @ClaireW_UK and @smithhazelann. 
Figure 2: Tweetfest 2016 schedules from the UK and Australia

A. The 2016 UK Tweetfest schedule. The times, dates, titles and presenters of the chats were all included in the schedule as well as on the website and this was advertised prior to the event

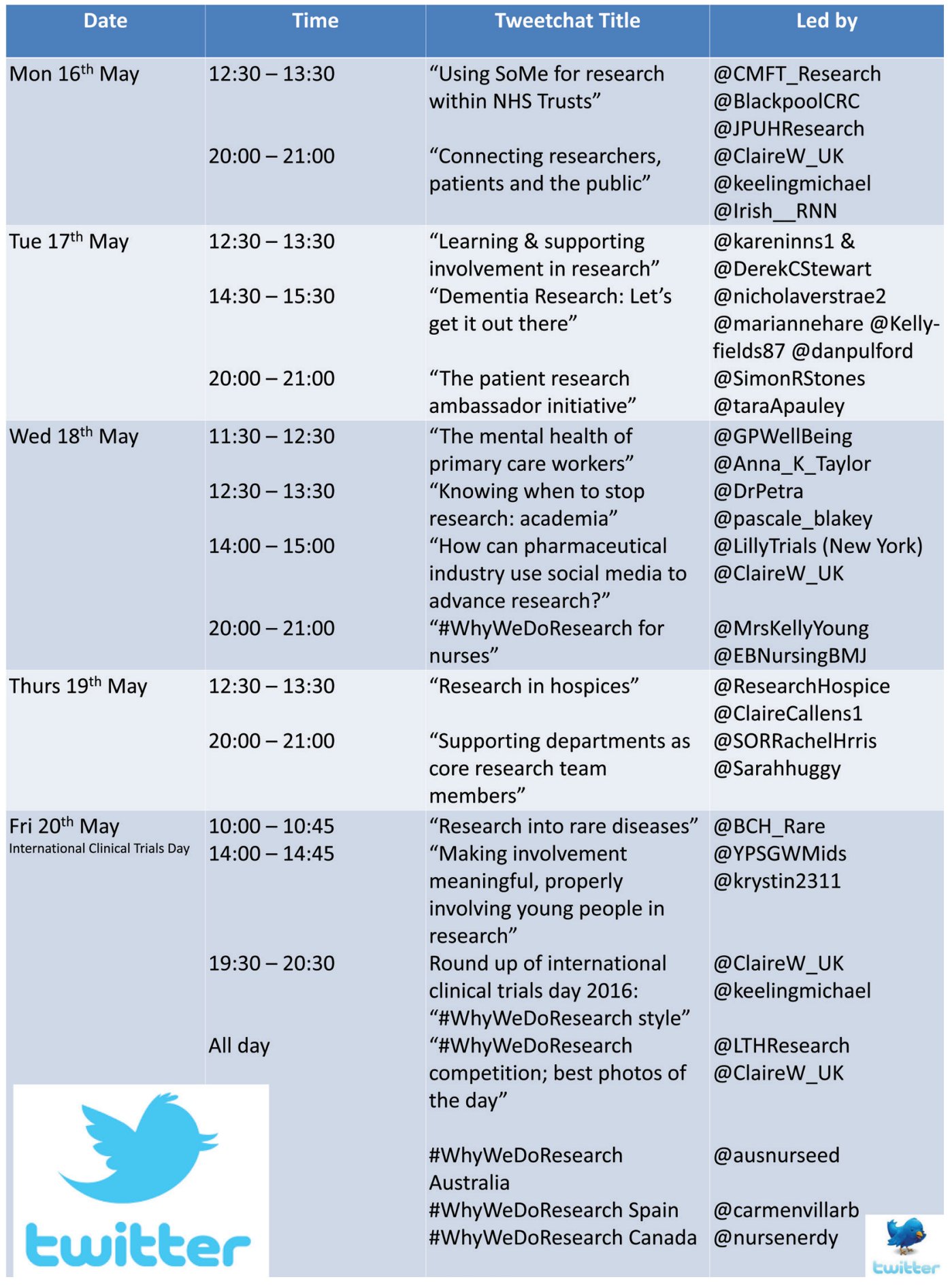


B. The Australian event was hosted by @AusNurseEd and ran for several days in May

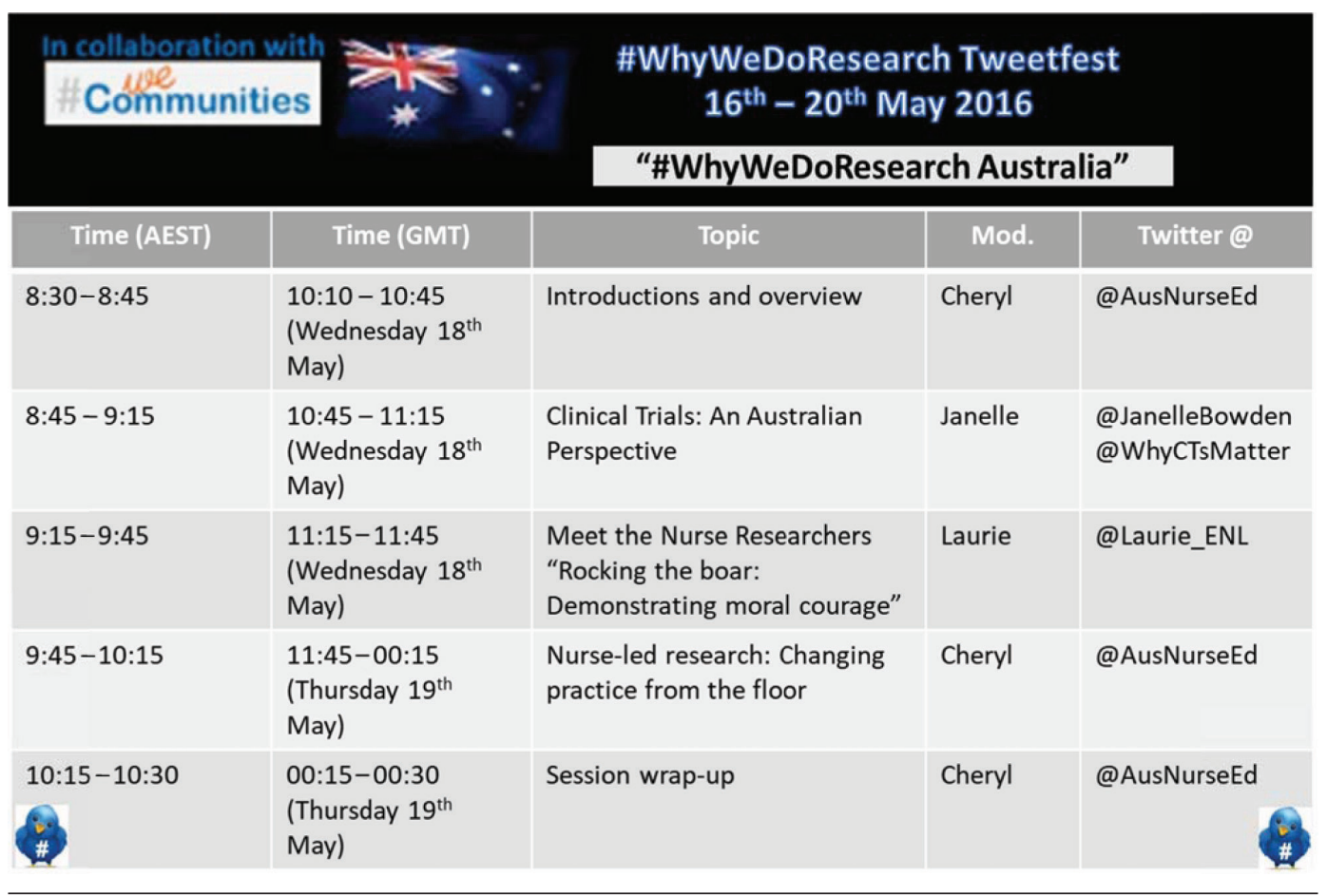

Week 1 of the 2017 Tweetfest dedicated every evening to patient and public tweetchats; other tweetchats were interspersed throughout the days. Some patients contacted the organizer directly to request a hosting position and others - those who had shown interest in the campaign previously or who had hosted tweetchats before - were approached. Patient hosts chose their own tweetchat titles and subjects, which were reviewed in line with all others to ensure no duplication of content. Hosts were further supported in the design of questions, to build confidence if they were unsure about the approach and to allow for open discussion.

\section{Limitations}

\section{Social media as a stand-alone tool}

Not all members of the public, or indeed health-care staff, are active on social media platforms. This may be due to lack of access to technology, or issues with confidence in using technology, and particularly in using social media platforms (Antheunis et al., 2013). Therefore, although Twitter was the social media platform used in this campaign, it should not be used as a stand-alone tool for raising research awareness. To address this, \#WhyWeDoResearch campaign followers also host events at their health-care organizations or in local communities. Previous examples of such events include stalls with 'pop-up' photo booths (see Figure 5). At these stands, the public, patients and staff may have photographs taken or share their experiences.

Some organizations have hosted live 'twitter walls' within their hospitals, where tweetchats are linked to a television screen in lobbies and communication teams enter feedback to questions from patients or the public in real time. 
Figure 3: Tweetfest 2017 schedule

\begin{tabular}{|c|c|c|c|}
\hline \multicolumn{4}{|c|}{ \#WhyWeDoResearch Tweeffest Schedule 2017} \\
\hline $\begin{array}{l}\text { \#WhyWeDoResearch } \\
\text { Tweeffest } 2017 \text { Week } 1\end{array}$ & $\begin{array}{l}12: 00-13: 00 \\
\text { Lunchtime }\end{array}$ & $\begin{array}{l}\text { 15:00 }-16: 00 \\
\text { Afternoon }\end{array}$ & $\begin{array}{c}\text { 20:00 - 21:00 } \\
\text { Evening }\end{array}$ \\
\hline Monday $15^{\text {th }}$ May & $\begin{array}{l}\text { Research and evidence in } \\
\text { pharmacy: engaging to improve } \\
\text { patient care } \\
\text { @wepharmacists @PharmResUK } \\
\text { @rpharms }\end{array}$ & $\begin{array}{l}\text { Ambulance Research } \\
\text { @NWAmb_Duncan }\end{array}$ & $\begin{array}{l}\text { Young people's involvement in } \\
\text { research } \\
\text { @YPSGWMids }\end{array}$ \\
\hline Tuesday $16^{\text {th }}$ May & $\begin{array}{l}\text { Midwifery Research } \\
\text { @wemidwives } \\
\text { @researchmidwives }\end{array}$ & $\begin{array}{l}\text { How radiographers can make a } \\
\text { difference through research } \\
\text { @SORRachelHarris \& @kimbomeek } \\
\text { @SCORMembers }\end{array}$ & $\begin{array}{l}\text { \#WhyWeDoResearch/\#WeNurses/VIBRA } \\
\text { NT /HARISofthepossible collaborative } \\
\text { @ClaireW_UK, @wenurses } \\
\text { @ecpdCarolyn }\end{array}$ \\
\hline Wednesday $17^{7 \mathrm{~h}}$ May & $\begin{array}{l}\text { Increasing recruitment in } \\
\text { paediatric research } \\
\text { @Sharon_Kempson }\end{array}$ & $\begin{array}{l}\text { Research in Mental Health } \\
\text { @ssarahdickenss }\end{array}$ & $\begin{array}{l}\text { Why Research is Important to Patients } \\
\text { @SteelRoger \& @jenny_newman! }\end{array}$ \\
\hline Thursday $18^{\text {th }}$ May & $\begin{array}{l}\text { Hospice Research } \\
\text { @learnhospice \& @drol007 }\end{array}$ & $\begin{array}{l}\text { "Good Clinical Practice changes } \\
\text { and the effect on research" } \\
\text { @lrish_RNN (rish Research Nurse } \\
\text { Network) }\end{array}$ & $\begin{array}{l}\text { The role of the Patient Research } \\
\text { Ambassador (PRA) } \\
\text { @ Jenny_Newmanl \& @SimonStones }\end{array}$ \\
\hline Friday $19^{\text {th }}$ May & $\begin{array}{l}10.00 \text { Your research inspiration } \\
\text { @impsonResearch } \\
12.00 \text { "If and when to start research" } \\
\text { @DrPetra \& pascale_Blakey }\end{array}$ & $\begin{array}{l}\text { How to get the public involved in } \\
\text { research: Health \& Care Research } \\
\text { Wales @ResearchWales }\end{array}$ & $\begin{array}{l}\text { 17.00-18.00 "From labs to clinics: } \\
\text { translational research" @EmmaYhnell } \\
20.00 \text { International Research Nursing } \\
\text { @|ACRNUKandlre }\end{array}$ \\
\hline \multicolumn{4}{|c|}{ \#WhyWeDoResearch Iweeffest 2017 Week 2} \\
\hline Monday $22^{\text {nd }}$ May & $\begin{array}{l}\text { "Careers for Clinical Trial } \\
\text { Assistants / Clinical Support } \\
\text { Officers" } \\
\text { @ClaireW_UK \& @smithhazelann }\end{array}$ & $\begin{array}{l}\text { "Principal Investigators - who can } \\
\text { be one and how do you choose?" } \\
\text { @|rish_RNN \& @ClaireW_UK }\end{array}$ & $\begin{array}{l}\text { Research in the Trauma/Emergency } \\
\text { Healthcare setting } \\
\text { @EmAshworth @EMERGE_research }\end{array}$ \\
\hline Tuesday $23^{\text {rd }}$ May & $\begin{array}{l}\text { "Clinical Research Nurses; } \\
\text { Professional Identity" } \\
\text { @TinkleLin }\end{array}$ & $\begin{array}{l}\text { NIHR Accelerating Digital; digital } \\
\text { technologies in research, what } \\
\text { would help you? } \\
\text { @DigitalCRN @antheamould } \\
\text { @dollyblue3 }\end{array}$ & $\begin{array}{l}\text { "Embedding research into clinical } \\
\text { practice" } \\
\text { @VickiConnyVicki @CMFI_Research } \\
\text { @JanetteDunkerll }\end{array}$ \\
\hline Wednesday $24^{\text {th }}$ May & $\begin{array}{l}\text { "Scholarship Opportunities for } \\
\text { Nurses, Midwives and AHPs" } \\
\text { @FNightingaleF }\end{array}$ & $\begin{array}{l}\text { "Feasibility for Research Studies" } \\
\text { @ClinEdge } \\
\text { 10:00-11:00 EST Hosted from Boston } \\
\text { 15:00-16:00 BST }\end{array}$ & $\begin{array}{l}\text { "Healthcare Research in Spain" } \\
\text { HOSTED IN SPANISH } \\
\text { @carmenvillarb }\end{array}$ \\
\hline Thursday $25^{\text {th }}$ May & $\begin{array}{l}\text { Primary Care Research } \\
\text { @NHS_NSResearch @PwSiobhan }\end{array}$ & $\begin{array}{l}\text { "The role of the care-giver in } \\
\text { research" } \\
\text { @LillyTrials } \\
1000-1100 \text { EST Hosted from } \\
\text { Indianapolis } \\
15: 00 \text { - 16:00 BST }\end{array}$ & $\begin{array}{l}\text { "Best practice in clinical research } \\
\text { nurse orientation / induction" } \\
\text { @SRNCNI (Scottish Research Nurse } \\
\text { and Co-ordinators Network) } \\
\text { @gordonhill @ @balmedieedwards }\end{array}$ \\
\hline Friday $26^{\text {th }}$ May & $\begin{array}{l}\text { "What makes a good research } \\
\text { environment for researchers?" } \\
\text { @Councilofdeans }\end{array}$ & $\begin{array}{l}\text { Tweeffest round-up } 2017 \\
\text { @ClaireW_UK @smithhazelann }\end{array}$ & Tweetfest hosted by @ClaireW_UK \\
\hline
\end{tabular}

\#WhyWeDoResearch also host monthly guest blogs, which are written by patients and staff sharing their experiences of research. On the \#WhyWeDoResearch website there is an option to comment on and discuss the guest blogs. This provides another forum for the public, patients and staff to engage with each other, commenting on and discussing health-related research.

\section{Global inclusivity}

In ensuring the \#WhyeDoResearch campaign was inclusive to the global community throughout Tweetfest, different time zones posed a potential problem for participation. Strategies employed to combat this included scheduling tweetchats towards the afternoon and evening Greenwich Mean Time where possible, which equates to European Standard Time morning and lunchtimes (with others fitting in between), and inviting people to host tweetchats from their own country and at a time that was most suited to themselves and their followers. The same hashtag was used throughout, which allows people to catch up at a later, more convenient, time if they want to. 
Figure 4: Tweetfest 2018 schedule

\begin{tabular}{|c|c|c|c|}
\hline \multicolumn{4}{|c|}{ \#WhyWeDoResearch Tweetfest Schedule 2018} \\
\hline & $\begin{array}{l}\text { Lunch Time } \\
\text { (BST) 12:00-13:00 }\end{array}$ & $\begin{array}{c}\text { Afternoon } \\
\text { (BST) 15:00-16:00 }\end{array}$ & $\begin{array}{c}\text { Evening } \\
\text { (BST) 20:00-21:00 }\end{array}$ \\
\hline $\begin{array}{l}\text { Monday } \\
14^{\text {th }} \text { May }\end{array}$ & $\begin{array}{l}\text { Benefits and Disadvantages of } \\
\text { Social Media to Health: } \\
\text { @DerekCStewart }\end{array}$ & $\begin{array}{l}\text { Navigating the Ethics System } \\
\text { for your Research Studies: } \\
\text { @SimonRStones }\end{array}$ & $\begin{array}{c}\text { CTAs (Clinical Trial Assistants)- } \\
\text { Improve the Research Recipe: } \\
\text { @uoscares }\end{array}$ \\
\hline $\begin{array}{l}\text { Tuesday } \\
15^{\text {th }} \text { May }\end{array}$ & $\begin{array}{l}\text { Patient Voice in } \\
\text { Health Research: } \\
\text { @DerekCStewart }\end{array}$ & $\begin{array}{c}\text { Patient Recruitment for } \\
\text { Rare Diseases: } \\
\text { @ClinEdge \& @AskGuideStar \& } \\
\text { @BTC_Network }\end{array}$ & $\begin{array}{l}\text { Exploring the Relationship } \\
\text { between CRN/Ms \& their } \\
\text { Nursing/Midwifery Colleagues: } \\
\text { @GordonHill1 \& @SRNCN1 } \\
\text { \& @IACRNUKandIRE }\end{array}$ \\
\hline $\begin{array}{l}\text { Wednesday } \\
16^{\text {th }} \text { May }\end{array}$ & $\begin{array}{l}\text { Increasing Recruitment in } \\
\text { Paediatric Research: } \\
\text { @sharon_kempson }\end{array}$ & $\begin{array}{c}\text { Budget Negotiations \& } \\
\text { Financial Management in } \\
\text { Clinical Trials: } \\
\text { @ClinEdge \& @AskGuideStar \& } \\
\text { @BTC_Network }\end{array}$ & $\begin{array}{l}\text { Research Involving Adults } \\
\text { Who Lack The Capacity } \\
\text { To Consent: } \\
\text { @VickyLShepherd }\end{array}$ \\
\hline $\begin{array}{l}\text { Thursday } \\
17^{\text {th }} \text { May }\end{array}$ & $\begin{array}{c}\text { Research into Social Media as } \\
\text { a method of Consent for } \\
\text { Contact (ContactME-IBS): } \\
\text { @TinkleLin }\end{array}$ & 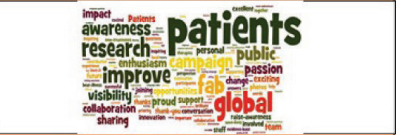 & $\begin{array}{l}\text { How Can We Improve } \\
\text { Collaboration in Research?: } \\
\text { @carmenvillarb } \\
\text { (This tweetchat will be hosted in Spanish) }\end{array}$ \\
\hline $\begin{array}{l}\text { Friday } \\
18^{\text {th }} \text { May }\end{array}$ & $\begin{array}{l}\text { Living Longer,Aging Well: } \\
\text { @NHS_NSResearch }\end{array}$ & $\begin{array}{l}\text { \#WhyWeDoResearch } \\
\text { tweetfest so far: } \\
\text { @smithhazelann }\end{array}$ & $\begin{array}{c}\text { Public Engagement \& } \\
\text { Involvement in Research: } \\
\text { @EmmaYhnell }\end{array}$ \\
\hline
\end{tabular}

Figure 5: Engaging with the \#WhyWeDoResearch campaign locally

A. Research team showing their support for the \#WhyWeDoResearch campaign using their \#WhyWeDoResearch placards

B. A \#WhyWeDoResearch stall with a 'pop-up' photo booth
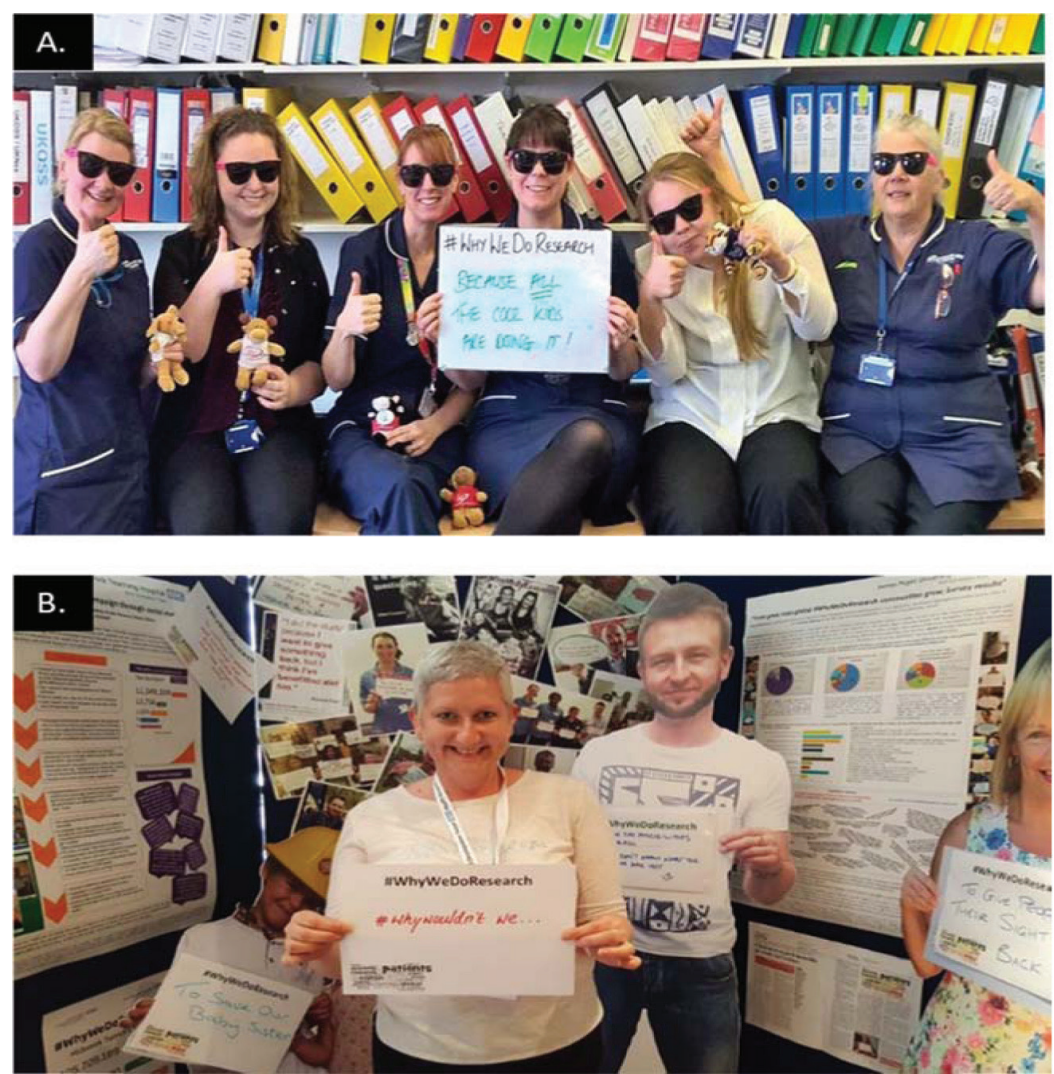

Credit: 5A @NNUHResearch

Credit: 5B @TaraAPuley 


\section{Funding and input}

The campaign is completely voluntary with no current funding. The input in terms of time required from the organizers was high level to support first-time hosts. However, the benefits far outweighed the limitations and are discussed below.

\section{Benefits}

\section{Reach}

The \#Why WeDoResearch campaign has demonstrated global impact and engagement. The hashtag has had over 400 million impressions to date. An 'impression' on Twitter measures the total number of times a tweet has been viewed or acted upon.

More than 45,000 individual social media accounts have participated in the campaign, spanning 23 countries. The 2017 Tweetfest reached over 50 million impressions in two weeks. Each tweetchat, both patient- and staff-led, throughout the 2017 Tweetfest achieved over one million impressions within their dedicated chat hour (statistics were kindly generated through @wegizmos). This demonstrates huge impact and engagement, thus highlighting the reach and power that positive social media use can have on health research.

\section{Feedback from 2017 Tweetfest hosts}

Hosts provided feedback about their experience of leading tweetchats via a SurveyMonkey questionnaire. Of the hosts that replied, 80 per cent of hosts had participated in a tweetchat prior to Tweetfest and 50 per cent had hosted a tweetchat prior to the event; therefore, 20 per cent of people had neither participated nor hosted before. Qualitative data collected from staff and patient hosts demonstrate the clear impact of the campaign (examples are provided in Figure 6). Themes included, but were not limited to: increased knowledge of research, increased awareness of research opportunities, and feeling part of a community.

\section{Networking}

All hosts fed back that their communities (personal and professional) had increased as a direct result of participating in the Tweetfest. Feedback from staff included an increase in patients asking about research opportunities in the months following Tweetfest. There were multiple reports of collaboration in research studies and of sharing of studies already open at sites to enable more opportunities for patients to join in from around the world. International discussions meant that assumptions and different working practices were challenged in a professional way, and learning ensued from this.

Patient hosts reported either an increase in their own followers or increases in communication with others with the same disease or research interest. All reported a consequent and immediate increase in their personal support networks, and some enrolled as ambassadors for charities in specific disease areas as a direct result of their experience in the \#WhyeDoResearch campaign.

The \#WhyWeDoResearch initiative described in this article is one aspect of the campaign and consequent community. The vision of the campaign is to raise research awareness and opportunities for patients, public and staff. Feedback from patient, public and staff hosts through the annual Tweetfest has demonstrated a new era of collaborative working, and shown important benefits in collaborative learning 
and sharing of ideas and knowledge. While limitations of the social media platform should be acknowledged, it is also possible to overcome these with preparation and perseverance, and when compared to the available benefits, the limitations pale in comparison.

Figure 6: Qualitative feedback collected from tweetchat hosts

A. Qualitative feedback from staff chat hosts

B. Qualitative feedback from patient chat hosts

A.

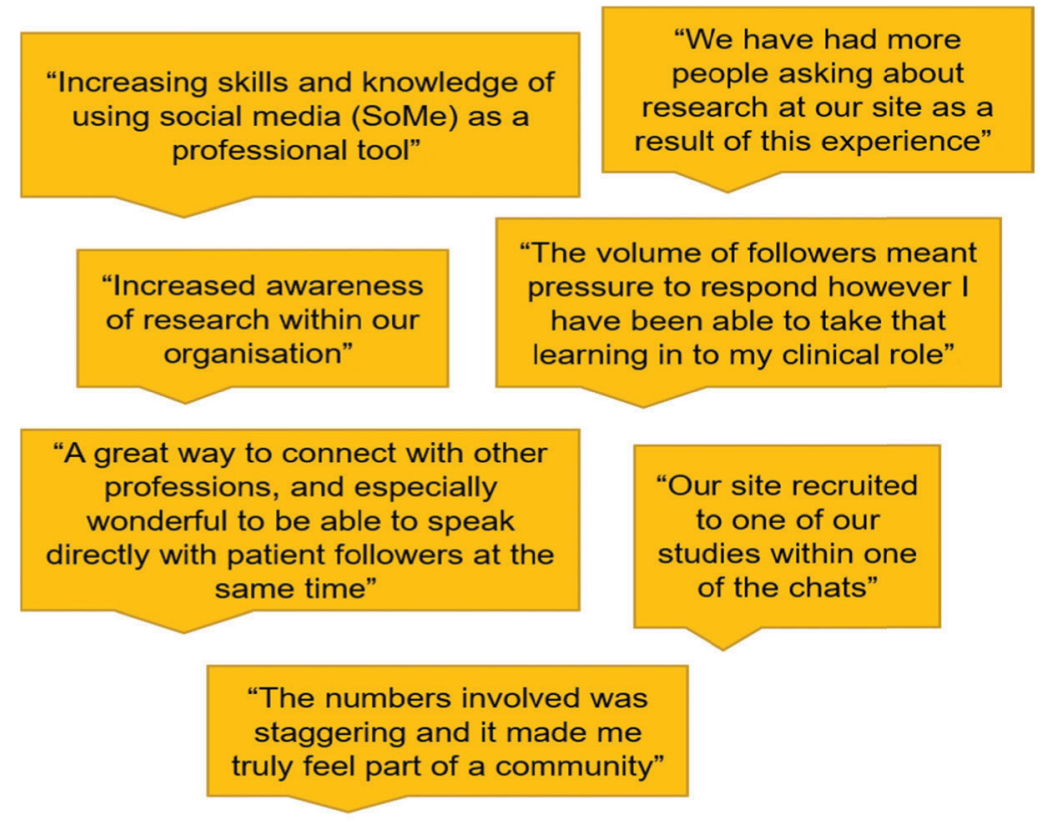

B.

"Realising that the staff are human and this campaign is more of a community where things really are on a level playing field for open discussion was wonderful"

"Patients are really valued in this campaign, it's the only of its kind to be so welcoming and open, count me in for next year"

"It was daunting hosting a tweetchat for the first time but we were supported in the development and during the chat; we learnt technical skills as well as organisational skills and understanding of how much work this takes behind the scenes"

"I've joined three studies since getting involved in tweetfest as I found out about them whilst engaging in the chats"

"I've told my family about the campaign; people share opportunities to participate in research using the hashtag and every now and again we fit the criteria so sign ourselves up"

"Hectic but brilliant, so wonderful to have co-hosts and feel supported", "the organisers and everyone involved really care for patients and our voices, that's the essence of the whole thing"
"We found out about research courses that are open to us as patients as well as to the staff, four of us joined, completed them and thoroughly enjoyed it" 


\section{Conclusion}

Social media has become a valuable platform for sharing voices and engaging healthcare staff and patients in research, although it should not be used as a stand-alone tool. There are many aspects to the \#WhyWeDoResearch campaign and community, and this paper has highlighted the many benefits of \#Why WoDesearch tweetchats in generating open discussion among patients, public and staff.

Patients are experts in their own right, and engaging and informing patients in research was the primary motivation for establishing the campaign, not forgetting that at various times in life, we are all patients. Both patients and staff reported positive outcomes from hosting tweetchats, both on personal and professional levels. Further formal research would be useful in contributing to the body of literature around lived experiences of patients and staff, with particular focus on the benefits and limitations of engaging with social media for health-care purposes.

The annual \#WhyWeDoResearch Tweetfest and ongoing campaign provide an example of how social media has been used effectively and positively as a tool to engage the public, patients and health-care staff in research.

\section{Acknowledgements}

We would like to thank Michael Keeling (@keeling_michael), Derek Stewart (@DerekCStewert), Wendy Mitchell (@WendyPMitchell), Russell Whitehouse, Kelly Young (@MrsKellyYoung), Teresa Chinn (@AgencyNurse), Nick Chinn (@NRCUK), all tweetchat hosts and the \#Why WeDoResearch community for participation in and support for the campaign.

\section{Notes on the contributors}

Emma Yhnell is a research fellow at Cardiff University. In 2016, she was awarded a fellowship, funded by the Welsh Government through Health and Care Research Wales, to translate her work on cognitive training into the Huntington's disease patient clinic. She became involved in the \#Why WeDoResearch campaign after volunteering to host a tweetchat as part of the 2017 Tweetfest. Alongside her research, she is passionate about public engagement and developing novel ways of engaging and involving patients and the public in research.

Hazel A. Smith was selected as the Communications Officer for the Irish Research Nurses Network (IRNN, @|rish_RNN) in January 2015. She was elected as Vice-Chair for the network in February 2018. The IRNN became \#WhyWeDoResearch collaborators in May 2015. In her role as Communications Officer and as Research Coordinator (Clinical Midwifery Manager II), Hazel has hosted \#WhyWeDoResearch tweetchats and written \#WhyWeDoResearch blogs. Hazel's research passions are maternal and child health and social epidemiology.

Kay Walker got involved in \#WhyWeDoResearch in 2016 to give the patient voice to debates, and to help clinicians think of things that patients and the general public want to know. She is also a researcher, so finds it interesting to hear what new research is being done and what new techniques are being used. Patients can interact with clinicians and researchers to ensure that research is being done in areas that are important to them. The campaign is important for research staff to see that their hard work is paying off and having an impact on the general public, and that care is being improved. 
Claire L. Whitehouse's professional role involves complete oversight of all research and the Clinical Research Nursing Teams. After qualifying in 2005, she worked in critical care, before moving into the research arena in 2010. Claire developed the \#WhyWeDoResearch campaign in 2014 and has led the developing community ever since. She has an MSc in nursing studies, is a member of the International Association of Clinical Research Nurses (@IACRN) and is a three times Florence Nightingale Foundation Scholar (@FNightingaleF). Her passions are patient care, and supporting capacity and capability of staff and patients to engage in research.

\section{References}

Antheunis, M.L., Tates, K. and Nieboer, T.E. (2013) 'Patients' and health professionals' use of social media in health care: Motives, barriers and expectations'. Patient Education and Counseling, $92(3), 426-31$.

Chauhan, B., George, R. and Coffin, J. (2012) 'Social media and you: What every physician needs to know'. Journal of Medical Practice Management, 28 (3), 206-9.

Cordoş, A.-A., Bolboacă, S.D. and Drugan, C. (2017) 'Social media usage for patients and healthcare consumers: A literature review'. Publications, 5 (2), Article 9, 1-10. Online. www.mdpi. com/2304-6775/5/2/9 (accessed 23 October 2018).

De Martino, I., D’Apolito, R., McLawhorn, A.S., Fehring, K.A., Sculco, P.K. and Gasparini, G. (2017) 'Social media for patients: Benefits and drawbacks'. Current Reviews in Musculoskeletal Medicine, 10 (1), 141-5.

Gibbs, C.L., Greaves, A., Keeling, M., Gaw, A. and O'Neill, F. (2015) 'Clinical research benefits go viral via Twitter'. Nursing Times, 111 (19), 16-17.

Greaves, F., Ramirez-Cano, D., Millett, C., Darzi, A. and Donaldson, L. (2013) 'Harnessing the cloud of patient experience: Using social media to detect poor quality healthcare'. BMJ Quality and Safety, 22 (3), 251-5.

Househ, M. (2013) 'The use of social media in healthcare: Organizational, clinical, and patient perspectives'. Studies in Health Technology and Informatics, 183, 244-8.

Househ, M., Borycki, E. and Kushniruk, A. (2014) 'Empowering patients through social media: The benefits and challenges'. Health Informatics Journal, 20 (1), 50-8.

Koumpouros, Y., Toulias, T.L. and Koumpourus, N. (2015) 'The importance of patient engagement and the use of social media marketing in healthcare'. Technology and Health Care, 23 (4), 495-507.

Moorhead, S.A., Hazlett, D.E., Harrison, L., Carroll, J.K., Irwin, A. and Hoving, C. (2013) 'A new dimension of health care: Systematic review of the uses, benefits, and limitations of social media for health communication'. Journal of Medical Internet Research, 15 (4), Article e85. Online. www.jmir.org/2013/4/e85 (accessed 23 October 2018).

Smailhodzic, E., Hooijsma, W., Boonstra, A. and Langley, D.J. (2016) 'Social media use in healthcare: A systematic review of effects on patients and on their relationship with healthcare professionals'. BMC Health Services Research, 16, Article 442, 1-14. Online. https://tinyurl.com/ ydfoyd7z (accessed 4 November 2018).

Ventola, C.L. (2014) 'Social media and health care professionals: Benefits, risks, and best practices'. Pharmacy and Therapeutics, 39 (7), 491-520. 